\title{
Nicotine Effects on Regional Cerebral Blood Flow in Awake, Resting Tobacco Smokers
}

\author{
EDWARD F. DOMINO, ${ }^{1 *}$ SATOSHI MINOSHIMA, ${ }^{2}$ SALLY GUTHRIE, ${ }^{3,5}$ LINDA OHL, ${ }^{4}$ LISONG NI, ${ }^{1}$ \\ ROBERT A. KOEPPE, ${ }^{2}$ AND JON-KAR ZUBIETA ${ }^{4,5}$ \\ ${ }^{1}$ Department of Pharmacology, University of Michigan, Ann Arbor, Michigan \\ ${ }^{2}$ Department of Internal Medicine (Nuclear Medicine), University of Michigan, Ann Arbor, Michigan \\ ${ }^{3}$ College of Pharmacy, University of Michigan, Ann Arbor, Michigan \\ ${ }^{4}$ Mental Health Research Institute, University of Michigan, Ann Arbor, Michigan \\ ${ }^{5}$ Department of Psychiatry, University of Michigan, Ann Arbor, Michigan
}

KEY WORDS nicotine; cerebral blood flow; awake; resting; tobacco smokers; oxygen 15 water

\begin{abstract}
The hypothesis for this research was that regional cerebral blood flow $(\mathrm{rCBF})$ would increase following nasal nicotine administration to overnight abstinent tobacco smokers in relationship to the known brain distribution of nicotinic cholinergic receptors (nAChRs). Nine male and nine female healthy adult smokers were studied. They abstained overnight from tobacco products for 10 or more hours prior to study the next morning. Nicotine nasal spray was given in doses of 1-2.5 $\mathrm{mg}$ total with half in each nostril while the subject was awake and resting in a supine position. Oleoresin of pepper solution in a similar volume was used as an active placebo to control for the irritating effects of nicotine. Both substances were given single blind to the subjects. Positron emission tomography (PET) with $\mathrm{H}_{2}{ }^{15} \mathrm{O}$ was used to measure $\mathrm{rCBF}$. The data from each subject volunteer were normalized to global activity to better assess regional brain changes. Both nasal nicotine and pepper spray produced similar increases in CBF in somesthetic area II, consistent with the irritant effects of both substances. The mean rCBF effects of nasal pepper were subtracted from those of nasal nicotine to determine the actions of nicotine alone. The latter produced increases in $\mathrm{rCBF}$ in the thalamus, pons, Brodman area 17 of the visual cortex, and cerebellum. Some brain areas that contain a large number of nAChRs, such as the thalamus, showed an increase in CBF. Other areas that have few nAChRs, such as the cerebellum, also showed an increase in relative $\mathrm{CBF}$. The hippocampal/parahippocampal areas showed greater regional decreases (left) and lesser increases (right) in CBF that correlated with the increase in plasma arterial nicotine concentrations. The results obtained indicate complex primary and secondary effects of nicotine in which only some regional brain CBF changes correlate with the known distribution of nAChR. No gender differences were noted. Synapse 38:313-321, 2000. ๑ 2000 Wiley-Liss, Inc.
\end{abstract}

\section{INTRODUCTION}

Studies on the functional significance of nicotinic cholinergic receptors (nAChRs) in the brain are an active area of research. It is of interest not only to scientists but also to members of society concerned with the issues of nicotine and tobacco addiction, health, compensation, economics, taxation, etc. Nicotine is the primary pharmacological agent in tobacco, with numerous complex actions (Larson et al., 1961; Ejrup, 1965; Larson and Silvette, 1968, 1971; Dunn, 1973; Balfour, 1984; Adlkofer and Thurau, 1985; Ney and Gale, 1989; Rand and Thurau, 1988; Clarke et al., 1995). The seminal U.S. Surgeon General's Report in
1998 stressed the addictive potential of nicotine in tobacco.

New brain imaging techniques have made such nicotine and tobacco research in humans feasible (Domino, 1995). One major action of nicotine demonstrated in animals is to stimulate the brainstem activating system resulting in short-lasting EEG activation and be-

Contract grant sponsor: U.S. Public Health Service; Contract grant number: DA-10992; Contract grant sponsor: National Institute on Drug Abuse, National Institutes of Health.

*Correspondence to: E.F. Domino, M.D., Department of Pharmacology, University of Michigan, Ann Arbor, MI 48109-0632.

Received 28 November 1999; Accepted 11 February 2000 
havioral arousal (Domino and Yamamoto, 1965; Yamamoto and Domino, 1965). Lesions of the brainstem prevent nicotine-induced EEG activation, suggesting important neuronal circuitry involving this area (Kawamura and Domino, 1969). In rat brain the autoradiographic distribution of ${ }^{3} \mathrm{H}$-acetylcholine $\left({ }^{3} \mathrm{H}\right.$ $\mathrm{ACh})$ and ${ }^{3} \mathrm{H}$-nicotine is quite different from ${ }^{125} \mathrm{I}-\alpha-$ bungarotoxin, indicating major regional brain differences in subtypes of nAChRs (Clarke et al., 1985). Both ${ }^{3} \mathrm{H}-\mathrm{ACh}$ and ${ }^{3} \mathrm{H}$-nicotine binding is highest in the interpeduncular nucleus, most thalamic nuclei, superior colliculus, medial habenula, presubiculum, layers I, III, and IV of the cerebral cortex, substantia nigra pars compacta, and the ventral tegmental area. The nicotinic cholinergic agonists, epibatidine and A-85380, when radiolabeled bind predominantly $\alpha 4 \beta 2 \mathrm{AChRs}$ in the thalamus and other brain areas in animals (Bottlaender et al., 1997; Ding et al., 1997; Horti et al., 1997; Chefer et al., 1998; Kimes et al., 1998; Koren et al., 1998; Mukhin et al., 1998; Vaupel et al., 1998). It is of interest to determine whether nicotine directly or indirectly affects similar brain structures in humans. Activation of nicotinic cholinergic receptors releases a large number of excitatory and inhibitory neurotransmitters and modulators. Therefore, both regional increases and decreases in cerebral blood flow were expected following nicotine administration where nAChR are located, as well as at more distant sites of neuronal activation or suppression.

A readily available form of nicotine approved by the U.S. Food and Drug Administration is a spray device for nasal administration. This route produces blood levels of nicotine which better mimic inhalation via tobacco smoke than either nicotine gum or skin patches. In the present study, nasal nicotine was compared to nasal oleoresin of pepper administration in a single-blind study of their effects on normalized rCBF in overnight, tobacco-deprived, awake, resting smokers.

\section{MATERIALS AND METHODS Subjects}

This study was approved by the Investigational Review Board for Human Subject Research at the University of Michigan Medical Center. All candidates who agreed to participate provided informed consent. Subjects were recruited through advertisements in local newspapers and via community bulletin boards. Candidates who appeared to be eligible on the basis of a preliminary telephone screen were invited to a screening interview, at which time the study was explained. A physical examination was performed and laboratory tests were obtained, including a complete blood count, electrolytes, liver function tests, urinalysis, and a urine toxicology screen for drugs of abuse. Additionally, all candidates underwent a psychiatric screening interview using the Structured Clinical Interview DSM IV
(SCID IV). Women were given a pregnancy test prior to inclusion in the study. Subjects who met the above criteria completed a Fagerström test to provide a preliminary assessment of the degree of nicotine dependence.

\section{Inclusion and exclusion criteria}

Subjects were male or female tobacco smokers who smoked 15-40 cigarettes per day, between 18-52 years of age, in good physical health, and not taking any medications (except oral contraceptives or replacement hormones). Individuals suffering from renal, hepatic, cardiovascular, hematological, neurological, psychiatric, or endocrinological disease were excluded. Fertile women who were not using an acceptable method of birth control (oral contraceptives, a barrier method, intrauterine device, or levonorgestrel implants) were excluded. Also, those who met criteria for psychoactive substance abuse disorder on the SCID IV were excluded, as were those who revealed evidence of recent use of an abused substance other than nicotine in the urine toxicological screen.

\section{Procedure}

Subjects were taught to use an FDA-approved nicotine nasal spray device prior to the study day. Subjects reported to the PET suite of the Nuclear Medicine Division of University Hospital at 8:00 AM on the day of the study, following overnight abstinence from tobacco products $(>10 \mathrm{~h})$. A sample of expired air was analyzed for carbon monoxide (CO) in parts per million (ppm). Expired air CO levels $>10 \mathrm{ppm}$ in the subject required an extensive interview to ascertain possible noncompliance with the no-smoking directive within the past $10 \mathrm{~h}$. Also, ECG and systemic arterial blood pressure were monitored throughout the study (Marquette Electronics, Milwaukee, WI; Series 7000 monitor).

Following an explanation of the imaging procedure, the subject lay supine in the PET gantry. For each subject, six PET scans were conducted at 12-15-min intervals using $\mathrm{H}_{2}{ }^{15} \mathrm{O}$ to determine $\mathrm{rCBF}$. The experimental session consisted of the following: scan \#1-5\% $\mathrm{CO}_{2}$ in $95 \% \mathrm{O}_{2}$; scan \#2-baseline; scan \#3-nasal spray of oleoresin of pepper placebo; scan \#4-recovery from pepper placebo; scan \#5-nasal spray of nicotine; scan \#6-partial recovery from nicotine. Both venous and arterial access lines were placed in the forearms of the subjects prior to the rCBF sessions for obtaining blood for plasma nicotine concentrations and arterial $\mathrm{pCO}_{2}$ and $\mathrm{pO}_{2}$ levels. The latter were performed by the University of Michigan Clinical Arterial Blood Gas Analysis Laboratory. About $3 \mathrm{~min}$ before the third and fifth scans, either placebo or nicotine spray $(0.5 \mathrm{mg} /$ spray) was administered intranasally. A total of $2-5$ sprays were administered, depending on the volunteer's ability to tolerate the nicotine. Arterial and ve- 
nous blood samples for nicotine and cotinine were withdrawn before and after the fifth and sixth scans. Samples were drawn prior to, and about 3, 6, 10, 15, 20, and $30 \mathrm{~min}$ following nicotine administration. Blood samples were collected in standard $5 \mathrm{ml}$ EDTA vacutainer tubes and stored immediately on crushed ice. Immediately following completion of the study the samples were centrifuged and plasma aliquots were frozen at $-20^{\circ} \mathrm{C}$ until analysis. Venous and arterial samples were analyzed for nicotine and cotinine using HPLC techniques (Hariharan et al., 1988). The nicotine and cotinine data have been reported in detail elsewhere (Guthrie et al., 1999).

\section{PET imaging and data analysis}

PET imaging was performed using a Siemens/CTI 931/08-12 scanner that collects 15 tomographic slices with a slice-to-slice separation of $6.75 \mathrm{~mm}$ (Spinks et al., 1988). A patient's head was positioned in the PET gantry using a 3-min transmission scout view to cover the region from the top of the brain to the middle of the cerebellum. A 12-min transmission scan was then obtained for the purpose of attenuation correction of the emission scans. Head position was maintained by soft restraints and monitored by laser beams. For each emission scan, the subject received an i.v. injection of $50 \mathrm{mCi} \mathrm{H}_{2}{ }^{15} \mathrm{O}$. The $\mathrm{H}_{2}{ }^{15} \mathrm{O}$ was prepared in the University of Michigan Nuclear Medicine Cyclotron facility. Data acquisition began $5 \mathrm{sec}$ after the arrival of radioactivity in the brain and continued for $60 \mathrm{sec}$.

Small head motions during emission scans were corrected by an automated computer algorithm for each subject before analysis (Minoshima et al., 1993). Images were then transformed to the standard bicommissural stereotactic coordinate system (Talairach and Tournoux, 1988) using automated linear scaling and nonlinear warping algorithms (Minoshima et al., 1994), which permitted pixel-by-pixel analyses of cerebral activities across subjects in a reproducible manner. Pixel counts of each image set were normalized to whole brain activity prior to statistical analysis. Normalized pixel counts were used as a marker of regional neuronal activities (Fox and Raichle, 1984). Statistical subtraction analyses were performed across subjects for the following conditions. To examine changes in cerebral activities induced by nicotine alone, the data of scan \#2 (baseline) was subtracted from the data of scan \#5 (nasal spray of nicotine). Similarly, the data of scan \#2 was also subtracted from scan \#3 (nasal spray of oleoresin of pepper placebo) to detect changes in brain activities induced by the active placebo spray. Nicotine spray induced an irritating sensation in the nasal cavity that could be partially reproduced by the application of pepper placebo spray. To detect more specifically changes in brain activities induced by direct effects of nicotine in the central nervous system, scan \#3 data (pepper placebo) was also subtracted from scan \#5 (nicotine) to remove effects of nasal sensation. The other possible confounding factor was the direct effect of nicotine on cerebral vasculature that may have induced changes in cerebral blood flow independent from neuronal activities. To partially address this issue, the heterogeneity in regional vascular responsiveness was examined by subtracting the data of baseline scan \#2 from scan \#1 obtained with a vascular dilator $\left(5 \% \mathrm{CO}_{2}\right.$ in $95 \% \mathrm{O}_{2}$ ) and compared to the results of the nicotine spray. In order to examine the lasting effects of placebo pepper spray and nicotine spray, recovery scans (scans \#4 and \#6) were obtained after scan \#3 (pepper placebo) and scan \#5 (nicotine spray), respectively, and subtraction analyses with baseline scan \#2 were performed. In addition, the correlation between the arterial plasma nicotine concentration at the time of the changes in $\mathrm{rCBF}$ was investigated by imagebased correlational analysis. Gender differences in response to nicotine were also investigated by the subtraction analysis between male and female image results.

In the statistical subtraction analyses, only gray matter pixels (pixels with normalized activities $>60 \%$ of the global value) were included in the analyses. To compensate for small residual anatomic variations across subjects and to improve signal-to-noise ratios, a three-dimensional Gaussian filter (FWHM $9 \mathrm{~mm}$ ) was applied to each scan. For each subtraction analysis, one-sample $t$-statistic values were calculated for each pixel using a pooled variance across pixels (Worsley et al., 1992). The use of a pooled variance approximated a normal Gaussian distribution on resultant statistical maps. To detect areas of significant differences, a statistical threshold that controlled a Type-I error rate at $P=0.05$ for multiple comparisons was estimated at $Z=4.00$ using the Euler characteristic (Worsley et al., 1992) based on the number of pixels in the gray matter and image smoothness (Friston et al., 1991). In the correlation analysis, correlation coefficients between normalized pixel values and arterial nicotine levels were calculated on a pixel-by-pixel basis across subjects and then transformed to $Z$ values using a Fisher's transformation. A critical threshold to delineate brain activities significantly correlating with plasma nicotine was estimated at $Z=4.2$ based on the theory described above. In the analysis examining gender differences in brain response to nicotine, twosample $t$-statistic values were calculated between male and female groups on a pixel-by-pixel basis and then converted to $Z$ values using probability integral transformation (Friston et al., 1991). The critical threshold to determine brain activities that would show significant gender differences was estimated at $Z=4.0$.

\section{Medications}

Nasal nicotine spray was obtained by medical prescription from Dr. E.B. Nelson of McNeil Consumer 

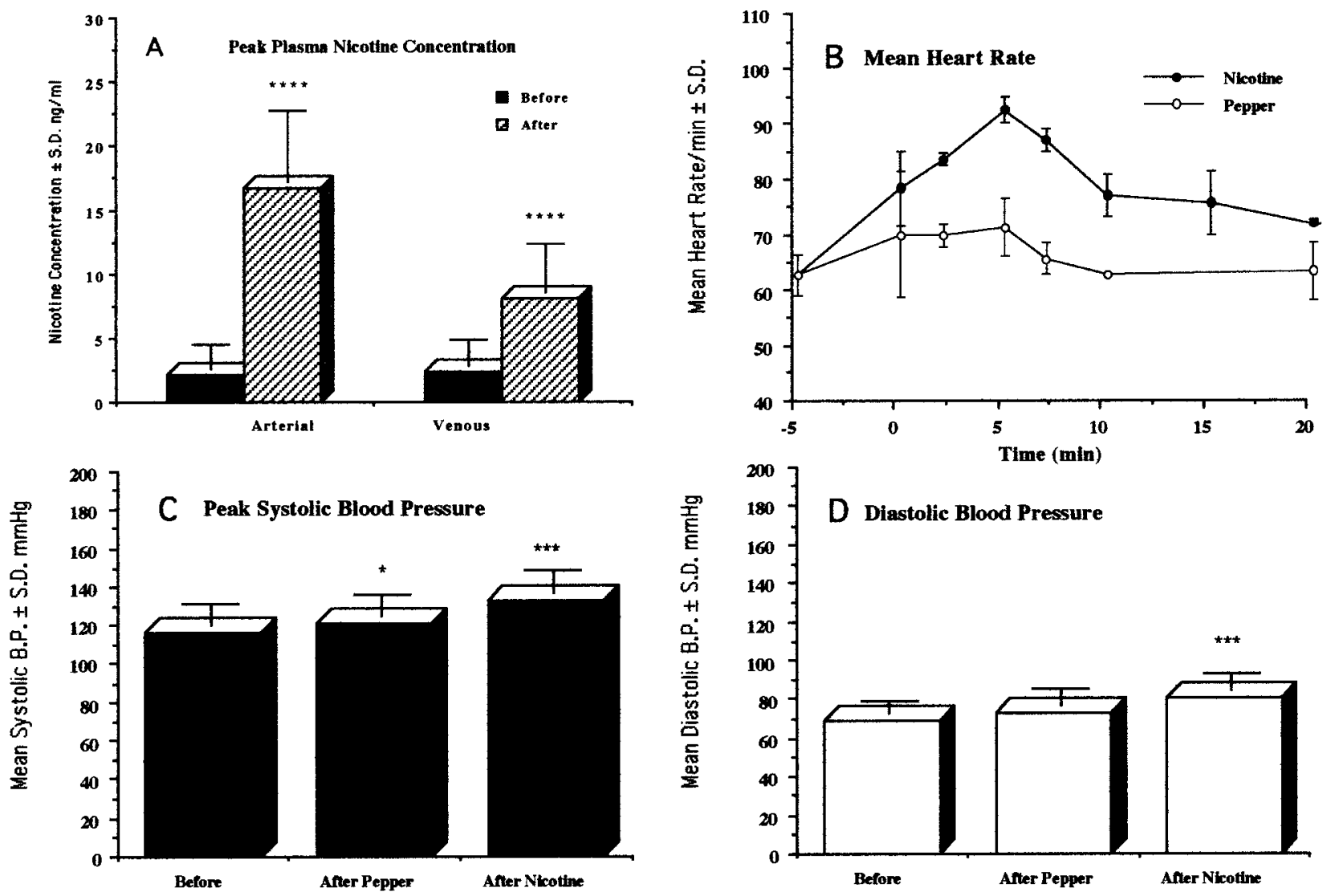

Fig. 1. Effects of nasal nicotine and pepper placebo spray on mean plasma nicotine concentrations and various cardiovascular parameters. A: Peak nicotine concentrations before and after nicotine nasal spray. B: Mean heart rate over time following nasal nicotine and

Products (Fort Washington, PA). Nasal oleoresin of pepper spray was obtained from Dr. K.O. Fagerström, Pharmacia and Upjohn A.B. (Helsingborg, Sweden).

\section{RESULTS \\ Plasma nicotine, cardiovascular, and subjective effects}

The mean data of plasma nicotine and its cardiovascular effects $(n=15-19)$ are summarized in Figure 1. As in Figure 1a, before nasal nicotine, the mean \pm SD plasma arterial concentration was $2.09 \pm 1.98$ and after the peak concentration was $16.73 \pm 5.62 \mathrm{ng} / \mathrm{ml}(P<0.0001)$. The mean \pm SD plasma venous concentration was $2.36 \pm 2.06$ and after $8.03 \pm 3.82 \mathrm{ng} / \mathrm{ml}(P<0.0001)$. The nicotine plasma levels decreased rapidly, consistent with its known alpha $t_{1 / 2}$ of about 8 min (not shown). Before nasal pepper, the mean heart rate \pm SD was $61.95 \pm 10.04 / \mathrm{min}$ and after $65.69 \pm 9.06 / \mathrm{min}(P>0.05)$. This slight increase continued for at least $15 \mathrm{~min}$. After nasal nicotine, the mean heart rate $\pm \mathrm{SD}$ was $92.74 \pm 11.33 / \min (P<$ $0.001)$. The nicotine-induced heart rate increase returned gradually toward control levels over the next $30 \mathrm{~min}$, but was still elevated. As illustrated in Figure 1c, the mean \pm SD peak systolic arterial blood pressure before nasal pep-

pepper spray. C: Mean peak systolic blood pressure. D: Mean diastolic blood pressure taken at the time of peak systolic pressure. ${ }^{*} P<$ $0.05, * * P<0.01, * * * P<0.001, * * * * P<0.0001, n=15$ to 19 subjects when data available.

per placebo was $116.22 \pm 10.76 \mathrm{~mm} \mathrm{Hg}$ and after $120.72 \pm 11.57 \mathrm{~mm} \mathrm{Hg}(P<0.05)$. The mean $\pm \mathrm{SD}$ systolic blood pressure after nasal nicotine spray was $132.63 \pm 11.94 \mathrm{~mm} \mathrm{Hg}(P<0.001$, see Fig. $1 \mathrm{C})$. The mean \pm SD diastolic blood pressure before nasal pepper spray was $68.21 \pm 7.54 \mathrm{~mm} \mathrm{Hg}$ and after $72.17 \pm 9.52$ $\mathrm{mm} \mathrm{Hg}(P>0.05$, Fig $1 \mathrm{D})$. The mean $\pm \mathrm{SD}$ diastolic blood pressure after nasal nicotine spray was $80.16 \pm$ $9.49 \mathrm{~mm} \mathrm{Hg}(P<0.001)$. When the subjects were asked which spray was more likely nicotine the answers were random. In contrast, the investigators, even when blinded to which spray was given, could easily tell when nicotine was administered on the basis of its obvious cardiovascular effects.

\section{PET imaging results}

Nicotine nasal spray increased normalized cerebral blood flow in multiple structures of the brain (Fig. 2, Table I). A large increase was seen in the cerebellar hemisphere and vermis. Increased blood flow was also noted in the pons and thalamus bilaterally in these deep brain structures. Nicotine induced a neocortical increase in cerebral blood flow in the premotor cortex bilaterally, in the primary visual cortex, peaking in the 


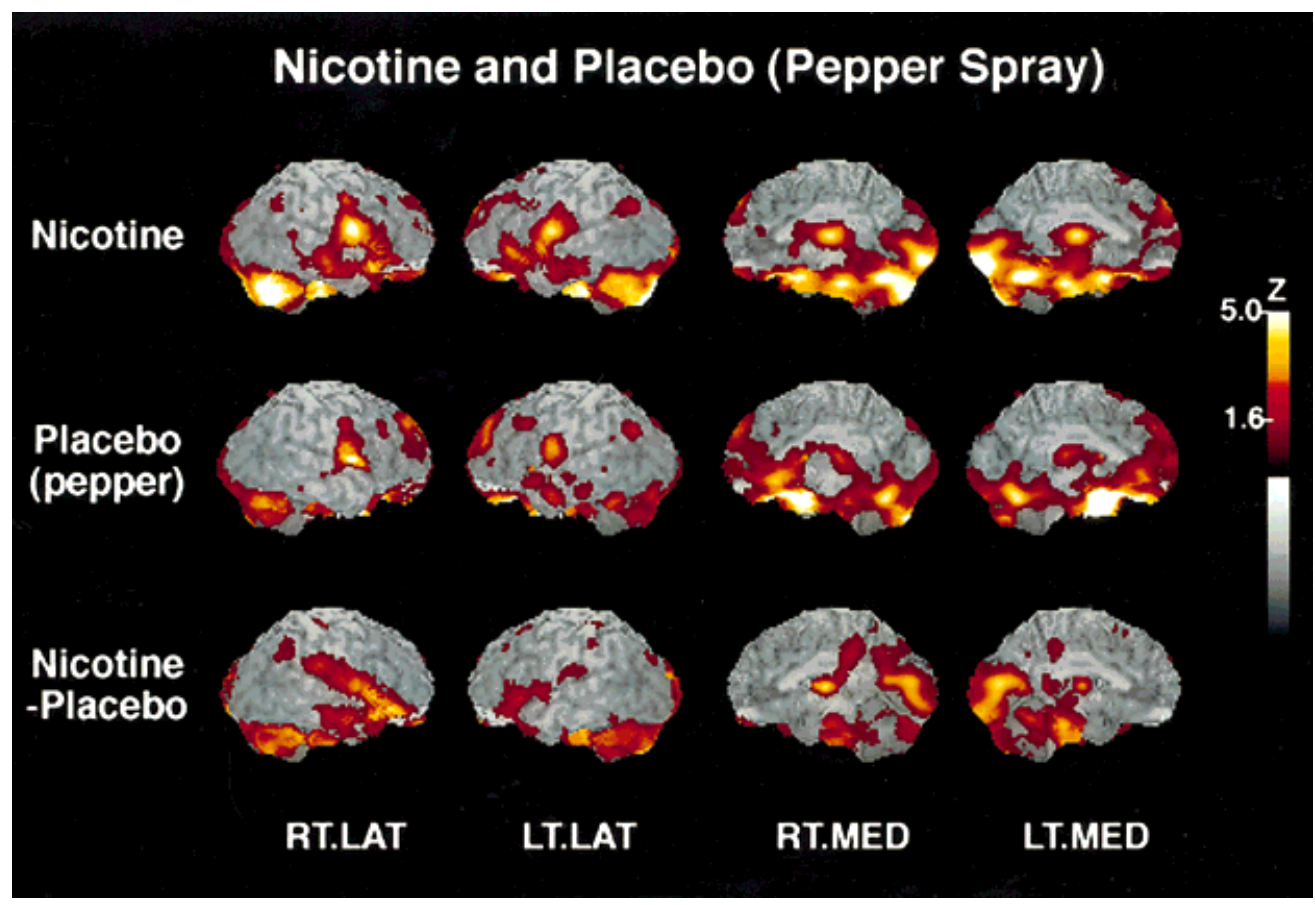

Fig. 2. Increased regional cerebral blood flow by nicotine and pepper placebo nasal spray. The results of the statistical subtraction analyses ( $Z$ score) of nicotine - baseline (first row), pepper placebo baseline (middle row), and nicotine - pepper placebo (bottom row) are superimposed on standard brain surface images. Right lateral (RT.LAT), left lateral (LT.LAT), right medial (RT.MED), and left medial (LT.MED) views of the brain are shown. Red to yellow pixels represent increased cerebral activities associated with statistical significance greater than $P<0.05$ (not corrected for multiple comparisons). Significant peak changes after controlling for multiple comparison are listed in Table I.

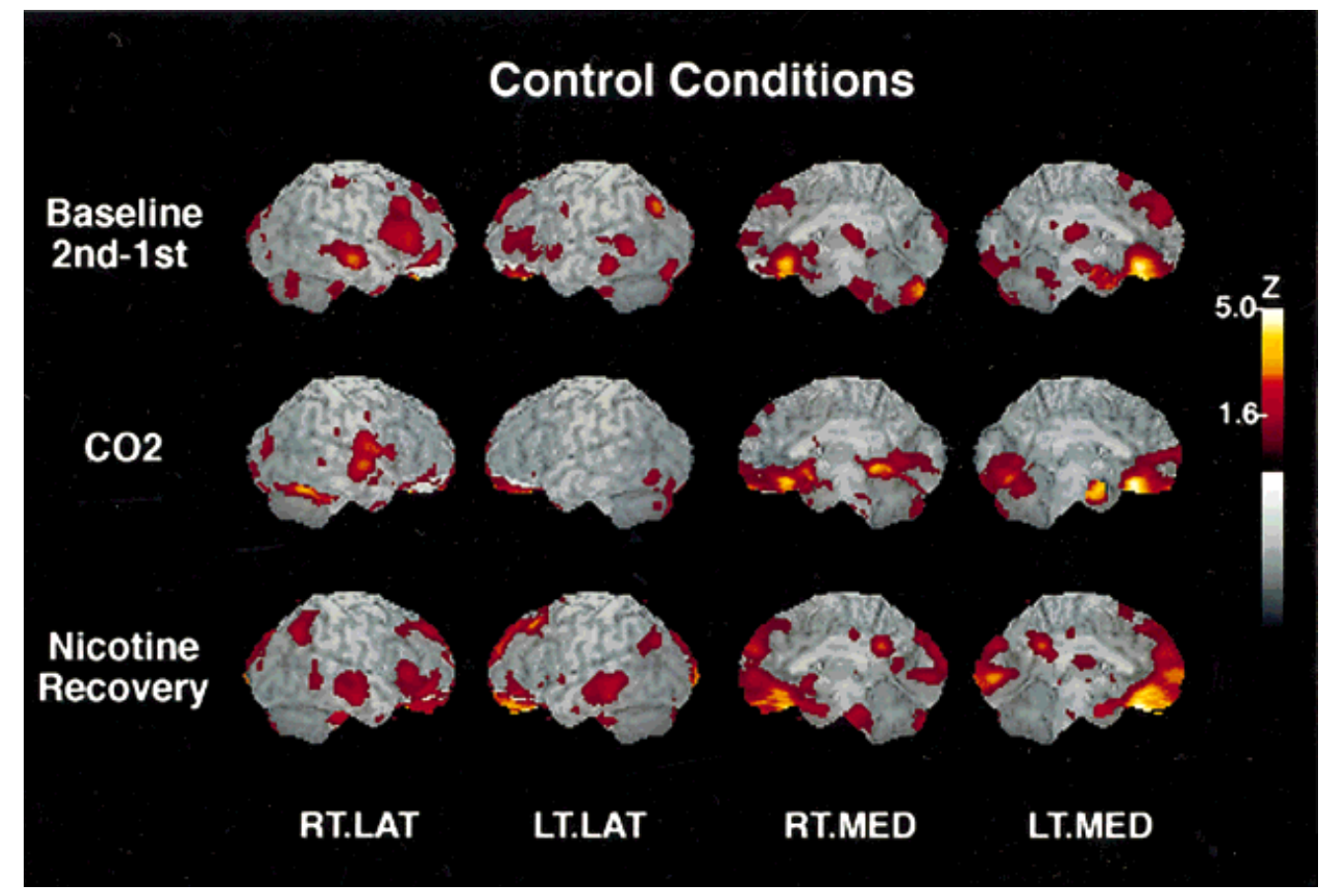

Fig. 3. Control scans obtained during the partial recovery phases of nicotine and pepper placebo nasal sprays and during $\mathrm{CO}_{2}$ inhalation. The color coding is the same as that in Figure 1. See also Table II. The results of 12-15 min recovery from nicotine spray (bottom row) and from pepper placebo spray (top row) are important controls. The mean scan with $\mathrm{CO}_{2}$ inhalation indicates the abstinent tobacco smokers had an increase in $\mathrm{rCBF}$ primarily in amygdala. 
TABLE I. Normalized changes in regional cerebral blood flow associated with nicotine and pepper placebo nasal sprays

\begin{tabular}{|c|c|c|c|}
\hline Structure & Coordinates* & $\begin{array}{c}\% \\
\text { Increase }\end{array}$ & $\begin{array}{c}Z \\
\text { score }\end{array}$ \\
\hline \multicolumn{4}{|c|}{ Nicotine minus baseline (scan 5 minus scan 2) } \\
\hline \multirow{6}{*}{ Left cerebellum } & $(28,-76,-40)$ & $12 \%$ & 6.3 \\
\hline & $(21,-80,-34)$ & $9 \%$ & 5.5 \\
\hline & $(24,-80,-27)$ & $7 \%$ & 5.2 \\
\hline & $(26,-60,-22)$ & $6 \%$ & 4.4 \\
\hline & $(42,-60,-29)$ & $7 \%$ & 4.3 \\
\hline & $(48,-51,-25)$ & $6 \%$ & 4.2 \\
\hline \multirow[t]{4}{*}{ Right cerebellum } & $(-12,-78,-34)$ & $10 \%$ & 5.8 \\
\hline & $(-35,-58,-27)$ & $8 \%$ & 5.7 \\
\hline & $(-37,-62,-36)$ & $9 \%$ & 5.1 \\
\hline & $(-21,-85,-25)$ & $6 \%$ & 4.0 \\
\hline Lingual gyrus & $(6,-91,-11)$ & $8 \%$ & 5.7 \\
\hline Vermis & $(1,-60,-22)$ & $8 \%$ & 5.6 \\
\hline Rectal gyrus & $(3,30,-22)$ & $11 \%$ & 5.7 \\
\hline Pons & $(-1,-24,-27)$ & $8 \%$ & 4.9 \\
\hline Right premotor & $(-60,3,16)$ & $7 \%$ & 4.9 \\
\hline Thalamus & $(1,-15,11)$ & $6 \%$ & 4.6 \\
\hline Left premotor & $(62,-1,16)$ & $6 \%$ & 4.5 \\
\hline Nasal sinus & $(1,5,-22)$ & $8 \%$ & 4.9 \\
\hline Right inferior temporal & $(-51,19,-16)$ & $7 \%$ & 4.3 \\
\hline Anterior cingulate & $(1,-8,32)$ & $-6 \%$ & -4.0 \\
\hline Left inferior temporal & $(33,-53,-4)$ & $-6 \%$ & -4.0 \\
\hline & $(39,-69,2)$ & $-6 \%$ & -4.5 \\
\hline Right inferior parietal & $(-21,-58,50)$ & $-6 \%$ & -4.2 \\
\hline Right inferior temporal & $(-42,-60,-2)$ & $-6 \%$ & -4.4 \\
\hline Right middle temporal & $(48,-53,-2)$ & $-7 \%$ & -4.7 \\
\hline \multicolumn{4}{|c|}{ Pepper placebo minus baseline (scan 3 minus scan 2 ) } \\
\hline Nasal sinus & $(8,12,-25)$ & $12 \%$ & 7.8 \\
\hline \multirow[t]{2}{*}{ Rectal gyrus } & $(3,30,-22)$ & $11 \%$ & 6.5 \\
\hline & $(-10,19,-20)$ & $7 \%$ & 4.8 \\
\hline Right premotor & $(-44,1,14)$ & $7 \%$ & 5.5 \\
\hline Right cerebellum & $(-12,-78,-38)$ & $9 \%$ & 5.3 \\
\hline \multirow[t]{3}{*}{ Vermis } & $(1,-62,-20)$ & $6 \%$ & 4.6 \\
\hline & $(-1,-60,-25)$ & $6 \%$ & 4.2 \\
\hline & $(1,-71,-38)$ & $7 \%$ & 4.0 \\
\hline Right ventral anterior cingulate & $(-10,28,-9)$ & $5 \%$ & 4.2 \\
\hline Left anterior insula & $(26,14,14)$ & $5 \%$ & 4.0 \\
\hline Left dorsal anterior cingulate & $(19,5,43)$ & $-5 \%$ & -4.0 \\
\hline Right medial frontal & $(-17,-10,52)$ & $-5 \%$ & -4.0 \\
\hline Right precuneus & $(-12,-53,52)$ & $-5 \%$ & -4.1 \\
\hline Right middle temporal & $(-39,-60,2)$ & $-5 \%$ & -4.3 \\
\hline Right superior frontal & $(-21,5,40)$ & $-6 \%$ & -4.8 \\
\hline \multicolumn{4}{|c|}{ Nicotine minus pepper placebo (scan 5 minus scan 3 ) } \\
\hline Left cerebellum & $(28,-72,-40)$ & $9 \%$ & 4.5 \\
\hline Thalamus & $(-3,-10,9)$ & $6 \%$ & 4.4 \\
\hline Primary visual cortex & $(3,-78,11)$ & $6 \%$ & 4.4 \\
\hline \multirow{4}{*}{ Right inferior frontal } & $(6,-94,-11)$ & & 4.0 \\
\hline & $(-48,32,-9)$ & $6 \%$ & 4.3 \\
\hline & $(-48,23,-14)$ & $6 \%$ & 4.3 \\
\hline & $(-55,21,0)$ & $5 \%$ & 4.1 \\
\hline Pons & $(10,-26,-22)$ & $6 \%$ & 4.1 \\
\hline Right superior temporal & $(-51,19,-16)$ & $6 \%$ & 4.1 \\
\hline Right middle frontal & $(-37,41,-14)$ & $6 \%$ & 4.1 \\
\hline Right inferior frontal & $(-57,17,2)$ & $5 \%$ & 4.0 \\
\hline
\end{tabular}

*In this and the following table coordinates are per Talairach and Tournoux, 1998. $(x, y, z)$, positive $x$ in the left hemisphere, positive $y$ in the anterior portion of the brain, positive $z$ in the superior portion of the brain.

$\%$ Change relative to global cerebral blood flow in this and the following table with $\mathrm{Z}$ scores $>4$ and $<-4$.

lingual gyrus, and right inferior temporal gyrus. There was a significant increase in blood flow within the rectal gyrus. However, a large increase in blood flow in the nasal cavity (presumably due to a direct mucosal effect) partially obscured the increase in the rectal gyrus.

The active pepper placebo spray produced an overlapping, but also distinct pattern of normalized increased brain blood flow compared to that of nicotine spray (Fig. 2, Table I). The overlapping areas of increased flow included the cerebellar hemisphere, ver-
TABLE II. Normalized changes in regional cerebral blood flow during recovery from nicotine and placebo pepper sprays and during $\mathrm{CO}_{2}$ inhalation

\begin{tabular}{lccr}
\hline & & $\%$ & $Z$ \\
Structure & Coordinates & Increase & score \\
\hline Recovery (nicotine) & minus & baseline (scan 6 minus scan 2) & \\
Rectal gyrus & $(6,30,-22)$ & $7 \%$ & 5.7 \\
& $(1,50,-18)$ & $7 \%$ & 4.1 \\
Ventral medial & & & \\
frontal & $(3,37,-11)$ & $6 \%$ & 4.3 \\
Right cerebellum & $(-28,-60,-16)$ & $-6 \%$ & -4.2 \\
Left cerebellum & $(35,-55,-18)$ & $-6 \%$ & -4.5 \\
Recovery (placebo) minus baseline $($ scan 4 minus scan 2$)$ & \\
Ventral medial & $(3,32,-14)$ & $6 \%$ & 4.5 \\
frontal & $(1,35,-20)$ & $6 \%$ & 4.5 \\
Rectal gyrus & $(3,30,-16)$ & $6 \%$ & 4.8 \\
CO ${ }_{2}$ minus baseline & $($ scan & minus scan 2) & \\
Rectal gyrus & $(24,-1,-18)$ & $5 \%$ & 4.2 \\
Left amygdala & $(-12,-44,-4)$ & $5 \%$ & 4.0 \\
Right posterior para- & $(-10,-60,27)$ & $-5 \%$ & -4.2 \\
hippocampal & & & \\
Right precuneus & & & \\
\hline
\end{tabular}

mis, premotor cortex, and rectal gyrus. An increase in cerebral blood flow in the right ventral anterior cingulate cortex and left anterior insula was unique to the pepper placebo. The overlapping areas of increased blood flow presumably represent brain structures responding to nasal irritation caused by both the nicotine and pepper sprays.

As noted in Table I, there were also statistically significant normalized decreases in $\mathrm{CBF}$ in various brain structures with both nicotine and the pepper placebo.

The mean normalized cerebral blood flow effects of nicotine spray minus those of the pepper spray were performed to determine more specifically the effects of nicotine not due to nasal irritation. This analysis was designed to subtract out brain activation associated with nasal irritation with nicotine. Significant increases in normalized blood flow were found in the cerebellum, thalamus, pons, right fronto-temporal operculum, and primary visual cortex (Fig. 2, Table I).

The recovery scan \#6 was obtained approximately 12-15 min after nicotine spray. It showed increased flow in the rectal gyrus, ventral medial frontal cortex, and cerebellum bilaterally (Fig. 3, Table II). However, other foci of significant activation seen with the nicotine spray were no longer present, indicating a relatively short duration of action of nicotine in those structures. In addition, pepper placebo recovery analysis also showed a similar pattern of residual blood flow increases in the rectal gyrus and ventral medial frontal cortex (Fig. 3, Table II), suggesting these changes may be associated with the application of irritable nasal sprays instead of specific effects of nicotine.

The correlation analysis between arterial nicotine levels and changes in normalized regional brain activities showed marginally significant "negative" correlation in the left parietal operculum $(Z=-4.3)$ and in the region of the left hippocampus/parahippocampal gyrus $(Z=-4.2$, Fig. 4). Interestingly, the right 


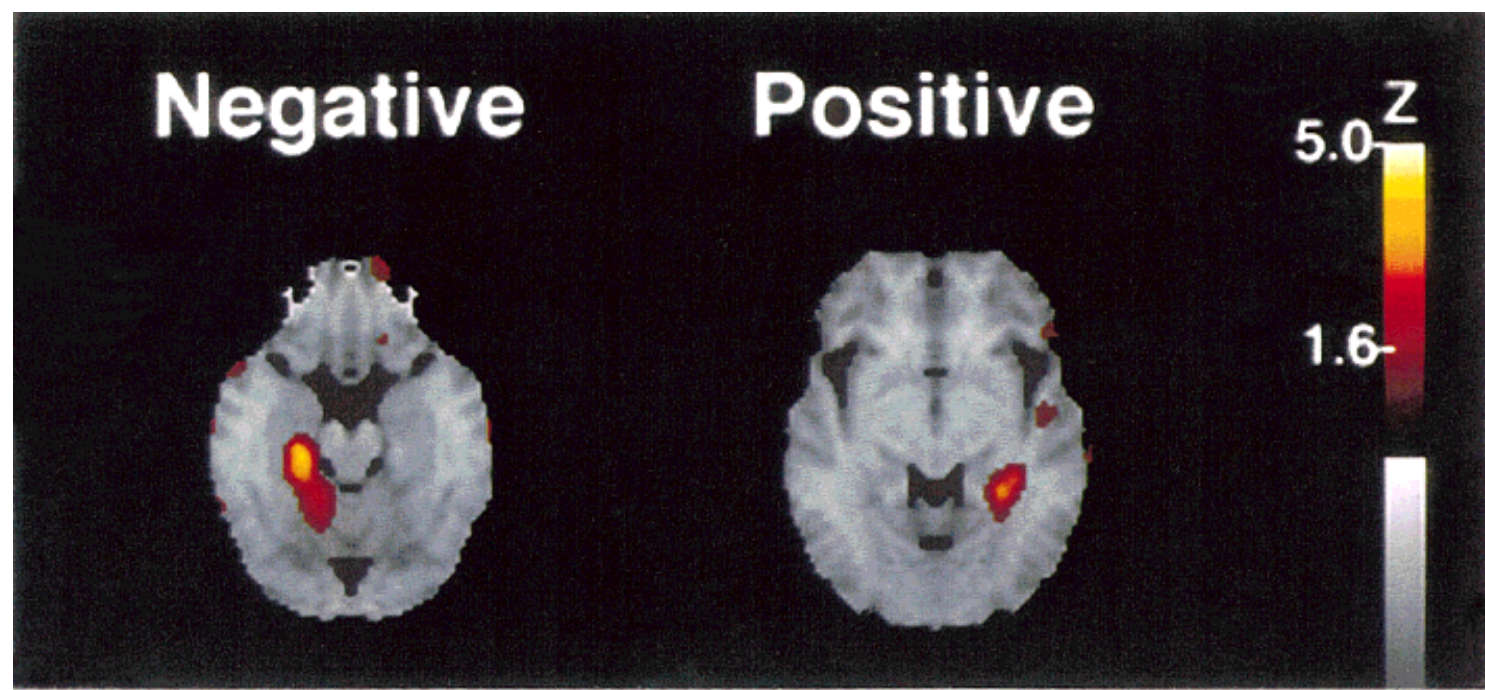

\section{$\mathrm{ACPC}-16 \mathrm{MM}$}

Fig. 4. Correlation between regional blood flow and arterial nicotine levels. A negative correlation indicates that $\mathrm{rCBF}$ decreases relative to an increase in arterial nicotine concentration. A positive

parahippocampal gyrus demonstrated a trend of "positive" correlation $(Z=3.4$, Fig. 4$)$. The analysis of gender differences did not show any brain structures where brain responses to nicotine were statistically different between male and female subjects.

The results of $5 \% \mathrm{CO}_{2} / 95 \% \mathrm{O}_{2}$ inhalation demonstrated three foci of significant relative regional increase in brain activities (Fig. 2, Table II). Except for the activation in the rectal gyrus, there was no overlap between changes seen with nicotine spray and those with $\mathrm{CO}_{2}$ inhalation. The mean \pm arterial $\mathrm{pCO}_{2}$ for scan 1 was $38.3 \pm 4.5 \mathrm{~mm} \mathrm{Hg}$ immediately after inhalation of $5 \% \mathrm{CO}_{2} / 95 \% \mathrm{O}_{2}$ and $35.8 \pm 3.7 \mathrm{~mm} \mathrm{Hg}$ after approximately $12-15$ min breathing room air for scan 2 . The mean $\pm \mathrm{SD}$ increment in $\mathrm{pCO}_{2}$ was $2.4 \pm 2.9$ $\mathrm{mm} \mathrm{Hg}$.

In contrast, the mean $\pm \mathrm{SD} \mathrm{pO}_{2}$ for scan 1 was $271.9 \pm 63.4$ and for scan $289.4 \pm 14 \mathrm{~mm} \mathrm{Hg}$. The mean $\pm \mathrm{SD}$ increment in $\mathrm{pO}_{2}$ was $182.5 \pm 64.8$. Therefore, the $\mathrm{pO}_{2}$ increased, whereas the $\mathrm{pCO}_{2}$ only increased negligibly during $5 \% \mathrm{CO}_{2} / 95 \% \mathrm{O}_{2}$ inhalation. In these tobacco-smoking volunteers who were abstinent overnight and breathing only room air, the mean $\mathrm{pCO}_{2}$ and $\mathrm{pO}_{2}$ levels did not change. They were similar in the normal range for the remaining five PET scans.

\section{DISCUSSION}

Nasal nicotine administration induces burning, stinging, and an odor (Hummel et al., 1992). The nicotine molecule contains a pyridine-pyrrolidine chemical structure; its odor is similar to that of pyridine and pyrroles. There is evidence that nicotine also selec-

\section{$\mathrm{ACPC}-4 \mathrm{MM}$}

6773 correlation indicates that $\mathrm{rCBF}$ increases with an increase in arterial nicotine concentration. The brain slice levels in stereotactic coordinates are below the anterior and posterior commissural line.

tively stimulates an olfactory nAChR (Edwards et al., 1987). Oleoresin of pepper induces burning and stinging but does not smell like nicotine and, presumably, is not acting through an nAChR mechanism. As described above, subjects blinded to the nasal sprays did not consistently identify correctly the nicotine from the pepper spray. However, even when blinded the investigators easily identified the nicotine spray on the basis of its obvious cardiovascular effects. It is of interest that tobacco smokers show tolerance and, when abstinent, have increased sensitivity to the odor of nicotine but no difference in their olfactory thresholds to menthol compared to nonsmokers (Rosenblatt et al., 1998). Although oleoresin of pepper is not a perfect placebo control, it is an appropriate active placebo for the irritant effects of nasal nicotine. The present study indicates that both irritants produced similar changes in rCBF in some brain areas such as somesthetic area II in the neocortex, thought to be involved in motor movement planning. An important data analysis issue is the fact that the rCBF changes were normalized to global activity. This is because the effects of nicotine on global activity are more variable. Most activation studies now use normalization of the data to better assess $\mathrm{rCBF}$ changes, as was done in the present study.

The PET data from the mean postplacebo scan \#3 was subtracted from the mean postnicotine scan \#5 to rule out the contribution of the nasal irritation produced by both agents. It was then possible to determine the predominant effects of nicotine alone. Clearly, nicotine increased $\mathrm{rCBF}$ in the thalamus, pons, and area 17 of the visual cortex. Therefore, these data are consistent with the known brain distribution of $\mathrm{nAChR}$ in 
both animals and man. In particular, the relative increases in CBF in the human thalamus and visual system agree with the London et al. (1988a,b) and London (1995) findings that nicotine increases rat thalamic and visual system glucose utilization. Furthermore, Domino et al. (2000) reported that nicotine also increases relative thalamic glucose utilization in humans.

A key experimental design feature was that the subjects in the present research were relaxed and awake with their eyes closed. They were requested to relax as much as possible and to try not to think of anything. Obviously, this is impossible to achieve, but is extremely important. Therefore, in this study the subjects' brains were at rest as much as possible in a PET suite, as opposed to being involved in a behavioral task. Thus, the results of this study are to be compared and contrasted to those in which subjects are at rest or involved in behavioral tasks (Flaum et al., 1997; Ernst et al., 1997, 1998; Ghatan et al., 1998; London et al., 1998; Nagata et al., 1998; Rose et al., 1998; Stein et al., 1998). These latter studies did not report any striking effects of nicotine and/or tobacco smoking on thalamic $\mathrm{CBF}$. Perhaps the behaviors studied increased thalamic blood flow and obscured the drug effect.

Roland (1993) summarized a number of human PET studies involving behavioral tasks alone that altered thalamic rCBF or rCMRglu. In general, the thalamus is activated when one is thinking. Tasks that require complex cognition, scrutinizing, attention, language, learning, recognition, vigilance, and sensory motor behaviors activate various thalamic nuclei. The PET scanner used in the present study was unable to differentiate whether specific relay or nonspecific thalamic nuclei had the greatest increase in $\mathrm{rCBF}$ following nicotine. The fact that the human thalamus is activated by nicotine is consistent with behavioral studies on the increased arousal and improvement in performance after tobacco smoking (Wesnes and Warburton, 1978; Sherwood, 1993, 1994; Domino et al., 1997a,b; Pritchard and Robinson, 1998; Warburton 1998).

An especially interesting finding in the present study is the relationship between the peak arterial nicotine concentrations and $\mathrm{rCBF}$ in the area of the hippocampus. It is well known that nAChRs, especially of the $\alpha 7$ subtype, are present and are involved in the behavioral/evoked potential phenomena of prepulse inhibition. Prepulse inhibition, which is deficient in schizophrenic patients and their relatives, is transiently normalized by nicotine (Adler et al., 1992).

The $5 \% \mathrm{CO}_{2} / 95 \% \mathrm{O}_{2}$ (scan 1) was used as a vascular control for nicotine. Inasmuch as $5 \% \mathrm{CO}_{2}$ is a cerebral vascular dilator and nicotine is a cerebral vascular dilator as well as a vascular constrictor, the rationale for the use of $\mathrm{CO}_{2}$ is weak, at best. Furthermore, with $95 \% \mathrm{O}_{2}$, one would expect a much higher arterial $\mathrm{pO}_{2}$ than the mean increase to $271.9 \mathrm{~mm} \mathrm{Hg}$. In addition, the slight arterial $\mathrm{pCO}_{2}$ increase to only $38.3 \mathrm{~mm} \mathrm{Hg}$ indicates that the face mask method used in this study must have allowed considerable mixing with room air, even though precautions were taken to prevent this. Therefore, the very limited $\mathrm{rCBF}$ changes restricted to only a few brain regions must be interpreted with this in mind. Furthermore, why the right precuneus showed a significant $(Z$ score $=-4.2$ ) decrease in $\mathrm{CBF}$ is unknown.

In conclusion, the present study with nicotine in overnight abstinent tobacco smokers supports a large body of both animal and human data that nicotine has very important regional CNS actions. These help to relate its reinforcing and tobacco dependence actions to specific brain structures.

\section{ACKNOWLEDGMENTS}

The authors gratefully acknowledge the support, advice, and encouragement of Dr. David E. Kuhl, without whom this study could not have been done. The expert technical assistance of J. Rothley, T. Hauser, P. Kison, E. McKenna, A. Weeden, L. Pastoriza, and J. Weeder was essential for the conduct of this study and is greatly appreciated.

\section{REFERENCES}

Adler LE, Hoffer LJ, Griffith J, Waldo M, Freedman R. 1992. Normalization of deficient auditory sensory gating in the relatives of schizophrenics by nicotine. Biol Psychiatry 32:607-616.

Adlkofer F, Thurau K, Editors. 1985. Effects of nicotine on biological systems, advances in pharmacological Sciences. Boston: Birkhäuser Verlag. p 1-646.

Balfour DJK (ed.) 1984. Nicotine and the tobacco smoking habit. International Encyclopedia of Pharmacology and Therapeutics, Section 114. New York: Pergamon Press. p 1-221.

Bottlaender M, Loc'h C, Kasiou M, Ottaviani M, Coulton C, Tavitian B, London E, Musachio J, Dnnals R, Mazière B. 1997. In vivo PET study of nicotinic acetylcholine receptors (nAChR) with [Br-76]bromoepibatidine. Soc Neurosci Abstr 23:Part 1, 382.

Chefer SI, Horti AG, Lee KS, Koren AO, Jones DW, Gorey JG, Links JM, Mukhin AG, Weinberger DR, London ED. 1998. In vivo imaging of brain nicotinic acetylcholine receptors with $\left[{ }^{123} \mathrm{I}\right]$ Iodo-A85380 using single photon emission computed tomography. Soc Neurosci Abstr 24:Part 1, 89.

Clarke PBS, Schwartz RD, Paul SM, Pert CD, Pert A. 1985. Nicotinic binding in rat brain autoradiographic comparison of $\left[{ }^{3} \mathrm{H}\right]$ acetylcholine, $\left[{ }^{3} \mathrm{H}\right]$ nicotine and $\left[{ }^{125}\right]-\alpha$-bungarotoxin. J Neurosci 5:1307-1315.

Clarke PBS, Quik M, Adlkofer F, Thurau K (eds.) 1995. Effects of nicotine on biological systems II. Advances in pharmacological sciences, Boston: Birkhäuser Verlag. p 1-403.

Ding Y-S, Fowler JS, Brady D, Gatley SJ, Volkow ND, Dewey SL, Liang F, Kuhar MJ, Carroll FJ. 1997. [ ${ }^{18}$ F]Norchloro-2-fluoroepibatidine studies of nicotinic acetylcholine receptors (nAChR) in living primate and postmortem human brain. Soc Neurosci Abstr 23:Part 1,382 .

Domino EF (ed.) 1995. Brain imaging of nicotine and tobacco smoking. Ann Arbor, MI: NPP Books. p 1-340.

Domino EF, Yamamoto K. 1965. Nicotine: effect on the sleep cycle of the cat. Science 150:637-638.

Domino EF, Ni LS, Zhang H. 1997a. Effects of tobacco smoking on human ocular smooth pursuit. Clin Pharmacol Ther 61:349-359.

Domino EF, Ni LS, Zhang H. 1997b. Sham and cigarette smoking effects on ocular smooth pursuit behavior and pupil diameter. Clin Pharmacol Ther 61:627.

Domino EF, Zubieta J-K, Guthrie S, Ohl L, Ni L, Koeppe R, Cross D, Minoshima S. 2000. Nicotine effects on regional cerebral metabolic rate in tobacco smokers. Clin Pharmacol Ther Abstr, March.

Dunn WL Jr (ed.) 1973. Smoking behavior: motives and incentives. Washington DC: VH Winston and Sons. p 1-309. 
Edwards DA, Mather RA, Shirley SG, Dodd GH. 1987. Evidence for an olfactory receptor which responds to nicotine-nicotine as an odorant. Experientia 43:868-873.

Ejrup B. 1965. The role of nicotine in smoking pleasure, nicotinism, treatment. In: von Euler US, editor. Tobacco alkaloids and related compounds. New York: Pergamon Press, Macmillan Co. p 333-346.

Ernst M, Matochik JA, Heishman SJ, Soria R, Jons PH, Zeffiro T, London ED. 1997. Cognitive activation in nicotine withdrawal. Soc Neurosci Abstr 24:Part 1, 257.

Ernst M, Jons PH, Matochik JA, Van Horn JD, Heishman SJ, Henningfield JE, London ED. 1998. Nicotine and cerebral blood flow during a working memory task. Soc Neurosci Abstr 24:Part 1, 752.

Flaum M, O'Leary DS, Cizadlo T, Arndt S, Hichwa R, Kirchner P, Andreasen NC. 1997. Acute effects of cigarette smoking on cerebral blood flow were assessed by $\mathrm{H}_{2}{ }^{15} \mathrm{O}$. Personal communication.

Fox PT, Raichle ME. 1984. Stimulus rate dependence of regional cerebral blood flow in human striate cortex, demonstrated by positron emission tomography. J Neurophysiol 51:1109-1120.

Friston KJ, Frith CD, Liddle PF, Frackowiak RS. 1991. Comparing functional (PET) images: the assessment of significant change. J Cereb Blood Flow Metab 11:690-699.

Ghatan PH, Ingvar M, Eriksson L, Stone-Elander S, Serrander M, Ekberg K, Wahren J. 1998. Cerebral effects of nicotine during cognition in smokers and non-smokers. Psychopharmacology 136: 179-189.

Guthrie SK, Zubieta JK, Ohl L, Ni L, Koeppe RA, Minoshima S, Domino EF. 1999. Arterial/venous plasma nicotine concentrations following nicotine nasal spray. Eur J Clin Pharmacol 55:639-643.

Hariharan M, Van Noord T, Greden JF. 1988. A high-performance liquid-chromatographic method for routine simultaneous determination of nicotine and cotinine in plasma. Clin Chem 34:724-729.

Horti AG, Koren AO, Scheffel U, Kimes AS, Ravert HT, Mathews WB, Musachio JL, Finley PA, Zhan Y, Dannals RF, London ED. 1997. $2-\left[{ }^{18} \mathrm{~F}\right]$ Fluoro-5 [2(s)-azetidinylmethoxy]pyridine, a radioligand for in vivo imaging of central nicotinic acetylcholine. Soc Neurosci Abstr 23:Part 1, 382.

Hummel T, Livermore A, Hummel C, Kobal G. 1992. Chemosensory event-related potentials in man: relation to olfactory and painful sensations elicited by nicotine. Electroencephalogr Clin Neurophysiol 84:192-195.

Kawamura H, Domino EF. 1969. Differential actions of $m$ and $n$ cholinergic agonists on the brainstem activating system. Int J Neuropharmacol 8:105-115.

Kimes AS, Vaupel DB, Mukhin AG, Chambers JK, Horti AG, Koren AO, Foster TD, London ED. 1998. Ex vivo and in vitro autoradiographic analysis of nicotinic acetylcholine receptors (nAChRs) using 5-[125 I]iodo-A-85380. Soc Neurosci Abstr 24:Part 1, 90.

Koren AO, Horti AG, Mukhin AG, Gündisch D, Kimes AS, Pickworth WB, Dannals RF, London ED. 1998. Synthesis and evaluation of halogenated analogs of A-85380 as ligands for nicotinic acetylcholine receptors. Soc Neurosci Abstr 24:Part 1, 85

Larson PS, Silvette H. 1968. Tobacco experimental and clinical studies: a comprehensive account of the world literature. Suppl 1. Baltimore: Williams and Wilkins. p 1-803.

Larson PS, Silvette H. 1971. Tobacco experimental and clinical studies: a comprehensive account of the world literature. Suppl 2. Baltimore: Williams and Wilkins. p 1-563.

Larson PS, Haag HB, Silvette H. 1961. Tobacco experimental and clinical studies: a comprehensive account of the world literature. Baltimore: Williams and Wilkins. p 1-932.

London ED. 1995. Mapping the cerebral metabolic response to nicotine. In: Domino EF, editor. Brain imaging of nicotine and tobacco smoking. Ann Arbor, MI: NPP Books. p 153-166.

London ED, Connolly RJ, Szikszay M, Wamsley JK, Dam M. 1988a. Effects of nicotine on local cerebral glucose utilization in the rat. J Neurosci 8:3920-3928.

London ED, Dam M, Fanelli RJ. 1988b. Nicotine enhances cerebral glucose utilization in central components of the rat visual system. Brain Res Bull 20:381-385.

London ED, Ernst M, Stapleton JM, Heishman SJ, Henningfield JE. 1998. Nicotine and functional brain imaging studies: metabolic effects in rats and humans and blood flow during cognitive activation. Proceedings SRNT, 4th Annual Meeting, New Orleans, LA.

Minoshima S, Koeppe RA, Fessler JA, Mintun MA, Berger KL, Taylor SF, Kuhl DE. 1993. Integrated and automated data analysis method for neuronal activation studies with ${ }^{15} \mathrm{O}$-water PET. In: Uemura K, Jones T, Lassen NA, Kanno I, editors. Quantification of brain function, tracer kinetics and image analysis in brain PET. Amsterdam: Excerpta Medica. p 409-415.

Minoshima S, Koeppe RA, Frey KA, Kuhl DE. 1994. Anatomic standardization: linear scaling and nonlinear warping of functional brain images. J Nucl Med 35:1528-1536.

Mukhin AG, Gåndisch D, Horti AG, Koren AO, Kimes AS, Vaupel DB, London ED. 1998. 5-Iodo-A85380 - a novel highly selective ligand for $\alpha 2 \beta 4$ subtype of nicotinic acetylcholine receptors. Soc Neurosci Abstr 24:Part 1, 85.

Nagata K, Yaguchi K, Park WM, Matsuoka S, Domino EF. 1998. Effects of cigarette smoking on brain function: combined ERP and PET studies. Proceedings, SRNT, 4th Annual Meeting, New Orleans, LA.

Ney T, Gale A (eds.) 1989. Smoking and human behavior. New York: John Wiley \& Sons. p 1-383.

Pritchard WS, Robinson JH. 1998. Effects of nicotine on human performance. In: Snel J, Lorist MM, editors. Nicotine, caffeine drinking-behaviour and brain function. Amsterdam: Harwood Academic Publishers. p 21-81.

Rand MJ, Thurau K. 1988. The pharmacology of nicotine. Washington DC: ICSU Press by IRL Press. p 1-418.

Roland PE. 1993. Brain activation. New York: Wiley-Liss. p 403-404. Rose JE, Behm FM, Westman EC, Johnson MP, Bates JE, Mathew RJ, London ED, Coleman RE, Hamblen S, Hawk TC, Turkington T. 1998. Acute effects of nicotine on regional and global cerebral blood flow. Proceedings, SRNT, 4th Annual Meeting, New Orleans, LA.

Rosenblatt MR, Olmstead RE, Iwamoto-Schaap PN, Jarvik ME. 1998 Olfactory thresholds for nicotine and menthol in smokers (abstinent and nonabstinent and nonsmokers). Physiol Behav 65:575-579.

Sherwood N. 1993. Effects of nicotine on human psychomotor performance. Hum Psychopharmacol 8:155-184.

Sherwood N. 1994. Cognitive and psychomotor effects of nicotine and cigarette smoking. Recent Adv Tobacco Sci 20:81-105.

Spinks TJ, Jones T, Gilardi MC, Heather JD. 1988. Physical performance of the latest generation of commercial positron scanner. IEEE Trans Nucl Sci 35:721-725

Stein EA, Pankiewicz J, Harsch HH, Cho JK, Fuller SA, Hoffmann RG, Hawkins M, Rao SM, Bandettini PA, Bloom AS. 1998. Nicotineinduced limbic cortical activation in the human brain: a functional MRI study. Am J Psychiatry 155:1009-1115.

Talairach J, Tournoux A. 1998. A coplanar stereotaxic atlas of the human brain. New York: Thieme.

US Surgeon General's Report. 1988. The health consequences of smoking: nicotine addiction. Washington DC: US Department of Health and Human Services. p 1-639.

Vaupel DB, Mukhin AG, Kimes AS, Horti AG, Koren AO, London ED. 1998. [ ${ }^{125}$ I]Iodo-A-85380: evaluation as a radiotracer for in vivo imaging of nicotinic acetylcholine receptors (nAChRs) in the mouse. Soc Neurosci Abstr 24:Part 1, 90.

Warburton DM. 1998. Caffeine, nicotine and attentional performance. In: Snel J, Lorist MM, editors. Nicotine, caffeine drinking-behaviour and brain function. Amsterdam: Harwood Academic Publishers. p 245-256.

Wesnes K, Warburton DM. 1978. The effects of cigarette smoking and nicotine tablets upon human attention. In: Thorton RE, editor, Smoking behaviour: physiological and psychological influences. London: Churchill-Livingstone. p 131-147.

Worsley KJ, Evans AC, Marrett S, Neelin P. 1992. A three-dimensional statistical analysis for CBF activation studies in human brain. J Cereb Blood Flow Metab 12:900-918.

Yamamoto K, Domino EF. 1965. Nicotine-induced EEG and behavioral arousal. Int J Neuropharmacol 4:359-373. 